\title{
Nitrato de amônio e nitrato de potássio no desenvolvimento in vitro de embriões somáticos de pupunheiras
}

\author{
Ammonium nitrate and potassium nitrate on in vitro peach palm somatic embryos development
}

\author{
Thaís Lobo dos Santos ${ }^{I}$ Cristina Vieira de Almeida ${ }^{\mathrm{II}}$ Gilvano Ebling Brondani' ${ }^{\mathrm{II}}$ \\ Marcílio de Almeida ${ }^{\mathrm{I}^{*}}$
}

\begin{abstract}
A pupunheira tem se mostrado boa alternativa à exploração extrativista de espécies como juçara e açaí. Porém, quando produzida via sementes apresenta plantio heterogêneo, o que torna a micropropagação ótima alternativa para seu cultivo em larga escala. O experimento objetivou avaliar a influência da interação entre nitrato de amônio e nitrato de potássio no enraizamento de microplantas obtidas a partir do desenvolvimento in vitro de embriões somáticos de pupunheiras, visando otimizar seu protocolo de micropropagação. Os embriões foram inoculados em meio MS com diferentes concentrações de $\mathrm{NH}_{4} \mathrm{NO}_{3}$ e $\mathrm{KNO}_{3}$. Aos 120 e 240 dias de cultivo, foram avaliados parâmetros morfofisiológicos do desenvolvimento radicular. Aos 120 dias, nas concentrações mais baixas de nitrogênio, houve estímulo ao crescimento das raízes e a maior ramificação radicular ocorreu com baixas concentrações de $\mathrm{NH}_{4} \mathrm{NO}_{3}$ e altas de $\mathrm{KNO}_{3}$. Aos 240 dias, notou-se redução do crescimento radicular $e$ raízes finas prevalecentes. Conclui-se que até 120 dias as microplantas devem ser mantidas em meio com concentrações menores de $\mathrm{NH}_{4} \mathrm{NO}_{3}$ e maiores de $\mathrm{KNO}_{3}$ que as empregadas no meio MS, voltando para as concentrações usuais após esse período.
\end{abstract}

Palavras-chave: Pejibaye, nitrogênio, Bactris gasipaes, micropropagação.

\section{ABSTRACT}

Pejibaye is a good alternative for the extractive exploration of species such as juçara and açaí. However, when it is produced by seeds its planting is heterogeneous, which makes micropropagation a good alternative for cultivation in large scale. This study aimed to evaluate the influence of the interaction between ammonium nitrate and potassium nitrate on peach palm somatic embryos rooting in vitro cultivated, for optimization of the micropropagation protocol. The embryos were inoculated in MS medium with different concentrations of $\mathrm{NH}_{4} \mathrm{NO}_{3}$ and $\mathrm{KNO}_{3}$. Morphophisyologic parameters of root development were measured at 120 and 240 days of cultivation. At 120 days, at lower nitrogen concentrations, roots were stimulated to grow and major root branching occurred at low concentrations of $\mathrm{NH}_{4} \mathrm{NO}_{3}$ and high concentrations of $\mathrm{KNO}_{3}$. At 240 days, there was a reduction of the root growing, with more percentage of thin roots. It was concluded that up to 120 days, the microplants should be cultivated in culture medium with lower concentrations of $\mathrm{NH}_{4} \mathrm{NO}_{3}$ and higher concentrations of $\mathrm{KNO}_{3}$ than those recommended by MS medium, and after this period they should be cultivated at the recommended doses.

Key words: Pejibaye, nitrogen, Bactris gasipaes, micropropagation.

O cultivo da pupunheira (Bactris gasipaes Kunth) tem se expandido devido a suas boas qualidades agronômicas e ecológicas (BOVI, 1997; TONET et al., 1999; ANEFALOS et al., 2007). Porém, a carência de campos de produção de matrizes com superioridade agronômica no Brasil e o sistema genético auto incompatível levam a plantios heterogêneos, com baixa produção e qualidade do palmito. Uma alternativa é o uso da técnica de micropropagação, que permite identificar genótipos adaptados a cada região, em larga

'Departamento de Ciências Biológicas, Escola Superior de Agricultura "Luiz de Queiroz" (ESALQ), Universidade de São Paulo (USP). Av. Pádua Dias, 11, CP 9, 13418-900, Piracicaba, SP, Brasil. E-mail: malmeida@esalq.usp.br. *Autor para correspondência. IIInVitroPalm Consultoria, Estudo e Desenvolvimento Biológico Ltda, Piracicaba, SP, Brasil.

I'Departamento de Ciências Florestais, ESALQ, USP, Piracicaba, SP, Brasil. 
escala e curto espaço de tempo (TOMBOLATO \& COSTA, 1998). A técnica tem se mostrado eficiente com uso de explantes provenientes de embriões somáticos, reversão de botões florais em gemas vegetativas (ALMEIDA \& KERBAUY, 1996) e de diferentes formulações do meio de cultura, que podem desencadear variados eventos fisiológicos (KIRBY et al., 1987), influenciando o desenvolvimento radicular. Nesse contexto, o trabalho teve por objetivo avaliar a influência da interação do nitrato de amônio e nitrato de potássio no enraizamento de microplantas de pupunheiras, visando otimizar o protocolo de micropropagação da espécie.

Foram utilizados embriões somáticos obtidos a partir da cultura in vitro de ápices caulinares de matrizes adultas, inoculados em meio MS (MURASHIGE \& SKOOG 1962) contendo modificações das concentrações das soluções de nitrato de amônio$\mathrm{NH}_{4} \mathrm{NO}_{3}\left(825 ; 1650 ; 2475\right.$ e 3300mg L $\mathrm{L}^{-1}$ ) e nitrato de potássio- $\mathrm{KNO}_{3}\left(950 ; 1900 ; 2850\right.$ e $\left.3800 \mathrm{mg} \mathrm{L}^{-1}\right)$, combinadas entre si, perfazendo um total de 25 tratamentos, com dez repetições. A testemunha consistiu de meio de cultura com as concentraçõespadrão utilizadas no meio MS. Aos 120 e 240 dias de cultivo, avaliou-se: comprimento e número de raízes, porcentagem de ramificação da raiz e de raízes finas $(<1 \mathrm{~mm})$, medianas $(1 \mathrm{~mm} \leq \mathrm{RM} \leq 1,5 \mathrm{~mm})$ e grossas $(>1,5 \mathrm{~mm})$. Utilizou-se o delineamento experimental inteiramente casualizado no arranjo fatorial $(5 \times 5)$ com parcelas subdivididas no tempo. Os dados foram submetidos ao teste de Bartlett em 5\% e à análise de variância (ANOVA), em 1\% e 5\% de probabilidade de erro. As médias foram comparadas por regressão polinomial em 5\% de probabilidade de erro.

Aos 120 dias, houve significância da interação entre $\mathrm{NH}_{4} \mathrm{NO}_{3}$ e $\mathrm{KNO}_{3}$ sobre a porcentagem de ramificação (Figura 1A), comprimento (Figura 1B) e porcentagem de raízes finas (Figura 1C). Já para número de raízes (Figura 1D) e porcentagem de raízes medianas (Figura 1E), houve influência significativa do $\mathrm{NH}_{4} \mathrm{NO}_{3}$ de maneira isolada e para a porcentagem de raízes grossas houve influência significativa do $\mathrm{KNO}_{3}$, também isoladamente (Figura 1F). Pelos pontos críticos estimados pela equação, as combinações que mais favoreceram a porcentagem de ramificação da raiz foram as próximas de $1101 \mathrm{mg} \mathrm{L}^{-1}$ de $\mathrm{NH}_{4} \mathrm{NO}_{3}$ e de $2178 \mathrm{mg} \mathrm{L}^{-1}$ de $\mathrm{KNO}_{3}$. Pelos dados reais, essas concentrações

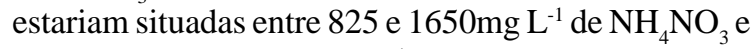
entre 1900 e $2850 \mathrm{mg} \mathrm{L}^{-1}$ de $\mathrm{KNO}_{3}$. Quanto ao comprimento da raiz, estimou-se pela equação as combinações próximas de $1287 \mathrm{mg} \mathrm{L}^{-1}$ de $\mathrm{NH}_{4} \mathrm{NO}_{3}$ e de $1727 \mathrm{mg} \mathrm{L}^{-1}$ de $\mathrm{KNO}_{3}$ como sendo as mais favoráveis e, pelos dados reais, as situadas entre 825 e $1650 \mathrm{mg} \mathrm{L}^{-1}$ de $\mathrm{NH}_{4} \mathrm{NO}_{3}$ e entre 950 e $1900 \mathrm{mg} \mathrm{L}^{-1}$ de $\mathrm{KNO}_{3}$.
Houve maior porcentagem de raízes finas nas concentrações entre 2475 e $3300 \mathrm{mg} \mathrm{L}^{-1}$ de $\mathrm{NH}_{4} \mathrm{NO}_{3}$ e entre 2850mg L-1 e 3800mg L-1 de $\mathrm{KNO}_{3}$, sendo que pela equação os pontos críticos estiveram também entre 2475 e $3300 \mathrm{mg} \mathrm{L}^{-1}$ de $\mathrm{NH}_{4} \mathrm{NO}_{3}$, porém com a concentração máxima de $\mathrm{KNO}_{3}$. As raízes grossas ocorreram em maior quantidade com 950mg $\mathrm{L}^{-1} \mathrm{e}$ 2850mg L ${ }^{-1}$ de $\mathrm{KNO}_{3}$. Para o número de raízes e porcentagem de raízes com diâmetro mediano observou-se tendência de diminuição da porcentagem com o aumento das concentrações de $\mathrm{NH}_{4} \mathrm{NO}_{3}$.

Aos 240 dias, houve significância da interação entre $\mathrm{NH}_{4} \mathrm{NO}_{3}$ e $\mathrm{KNO}_{3}$ sobre a porcentagem de raízes finas (Figura 2A). Já para o número de raízes (Figura 2B) e a porcentagem de ramificação da raiz (Figura 2C), houve influência significativa do $\mathrm{NH}_{4} \mathrm{NO}_{3}$, de maneira isolada. Para o número de raízes (Figura 2D), houve influência significativa apenas do $\mathrm{KNO}_{3}$. As raízes finas ocorreram em maior porcentagem nas interações mínimas e máximas dos dois sais. Os resultados evidenciaram, ainda, tendência de diminuição do número de raízes e de sua ramificação com o aumento da concentração de $\mathrm{NH}_{4} \mathrm{NO}_{3}$ e de aumento do número de raízes até a concentração de $2850 \mathrm{mg} \mathrm{L}^{-1}$ de $\mathrm{KNO}_{3}$.

Em alguns casos, o coeficiente de determinação $\left(\mathrm{r}^{2}\right)$ da equação apresentou valor baixo, devido à heterogeneidade dos dados amostrados. Nesses casos, atentou-se para as tendências de comportamento dos tratamentos sobre o desenvolvimento radicular das microplantas.

No metabolismo do nitrogênio, ocorre uma reprogramação do metabolismo de $\mathrm{C}$ e $\mathrm{N}$ pela presença do nitrato, ajustando a arquitetura da raiz ao estádio fisiológico da planta (STITT, 1999), sendo que altos níveis de $\mathrm{N}$ levam a mudanças na alocação e fenologia da planta. A alocação de recursos durante o crescimento vegetativo depende, ainda, da disponibilidade de nutrientes (MARSCHNER, 1995), sendo que a deficiência moderada de $\mathrm{N}$ inibe o crescimento da parte aérea e até estimula o da raiz (SCHEIBLE et al., 1997), o que poderia justificar o crescimento radicular mesmo sob baixas concentrações de $\mathrm{NH}_{4} \mathrm{NO}_{3}$.

$\mathrm{O} \mathrm{KNO}_{3}$ é um importante componente do meio de cultura por ter $\mathrm{N}$ e $\mathrm{K}$ controlando o desenvolvimento das raízes e por regular o potencial osmótico, respectivamente (RIBEIRO \& TEIXEIRA, 2008). Já a ramificação radicular depende do balanço entre baixas concentrações de $\mathrm{NH}_{4} \mathrm{NO}_{3}$ e altas de $\mathrm{KNO}_{3}$, 

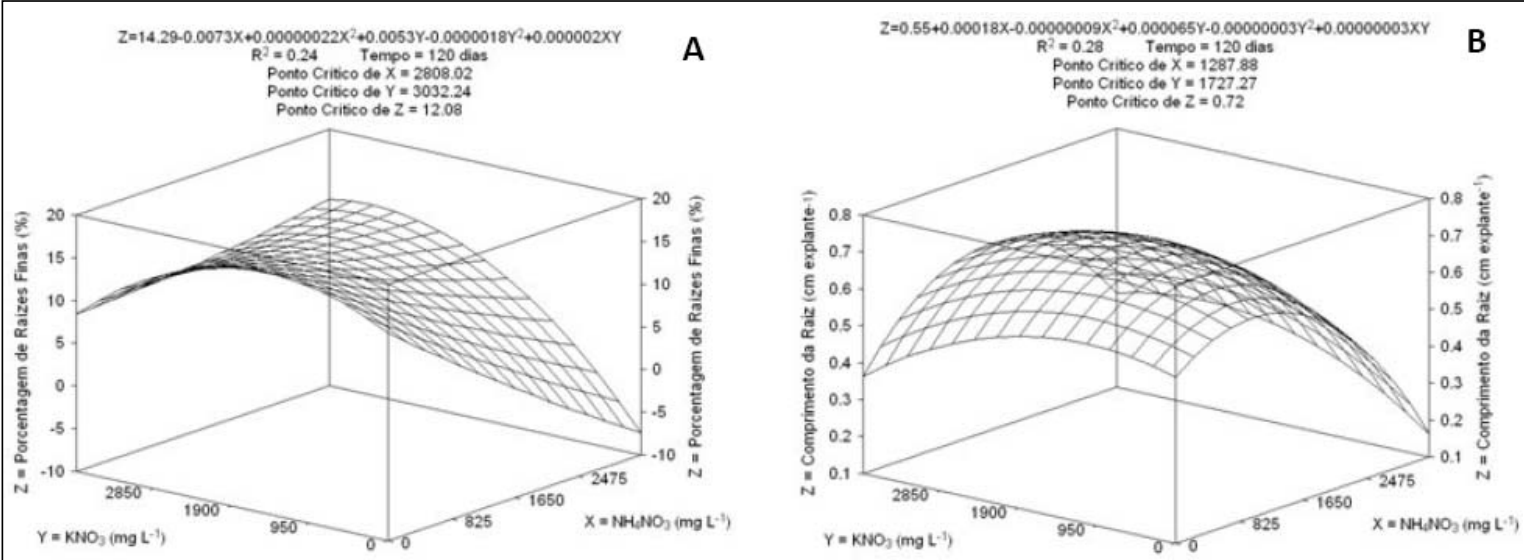

C
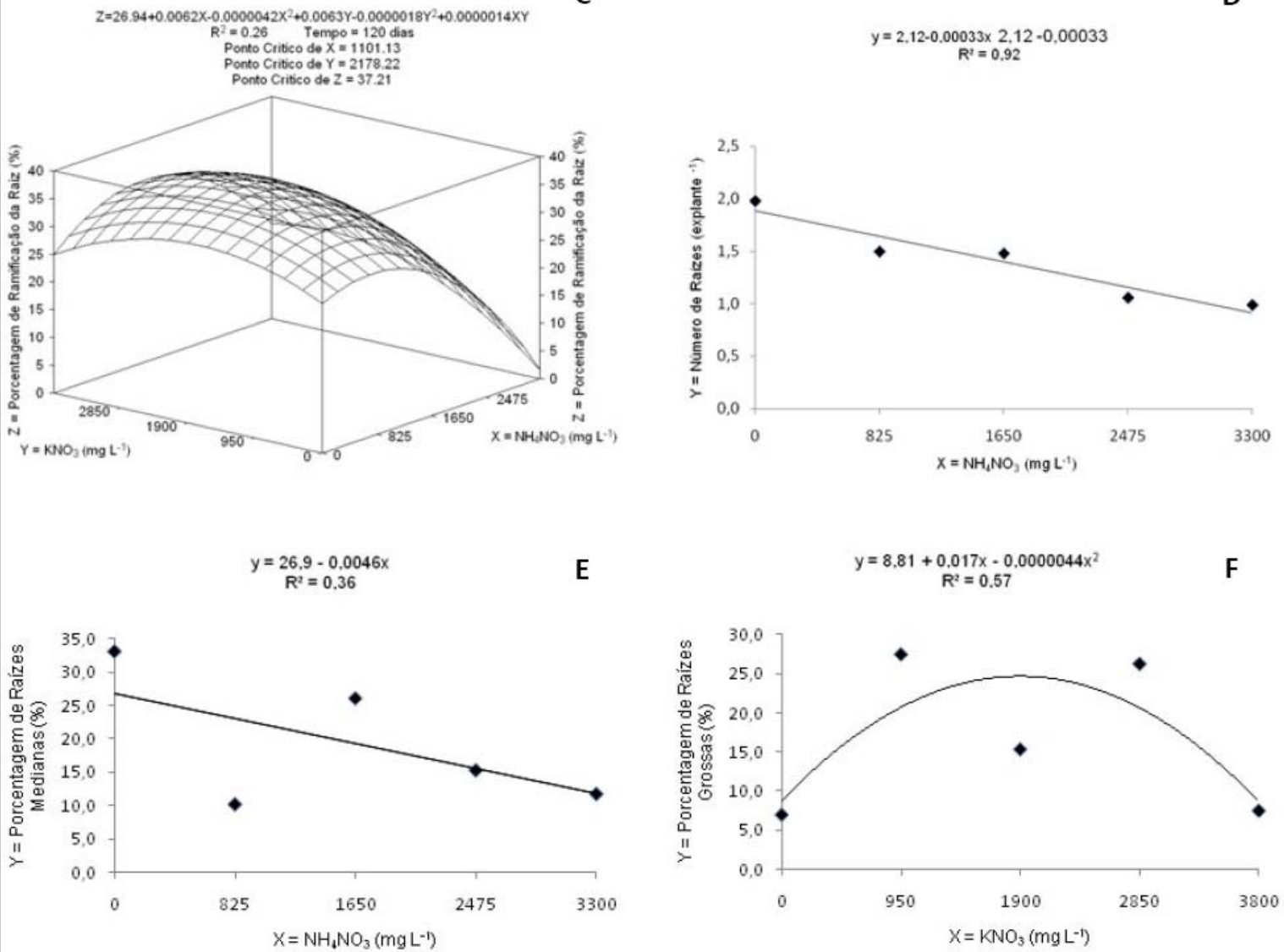

Figura 1 - Porcentagem de ramificação da raiz (A), Comprimento da raiz (B), Porcentagem de raízes finas (RF $<1 \mathrm{~mm}$ de diâmetro) (C) de microplantas de B. gasipaes desenvolvidas a partir de embriões somáticos em função das concentrações de $\mathrm{NH}_{4} \mathrm{NO}_{3}$ e $\mathrm{KNO}_{3}$, Número de raízes (D), Porcentagem de raízes medianas $(1 \mathrm{~mm}<\mathrm{RM}<1,5 \mathrm{~mm}$ de diâmetro) (E) de microplantas de B. gasipaes desenvolvidas a partir de embriões somáticos em função das concentrações de $\mathrm{NH}_{4} \mathrm{NO}_{3}$ e Porcentagem de raízes grossas (RG>1,mm de diâmetro) (F) de microplantas de $\boldsymbol{B}$. gasipaes desenvolvidas a partir de embriões somáticos em função das concentrações de $\mathrm{KNO}_{3}$, após 120 de cultivo in vitro.

pois o K é necessário para o crescimento da planta e o bom desenvolvimento da raiz e em baixas concentrações o estaria inibindo, sendo que altos níveis de nitrato geralmente inibem o crescimento e a quantidade de raízes laterais (GRIME et al., 1991; MARSCHNER, 1995).

Ciência Rural, v.40, n.7, jul, 2010. 

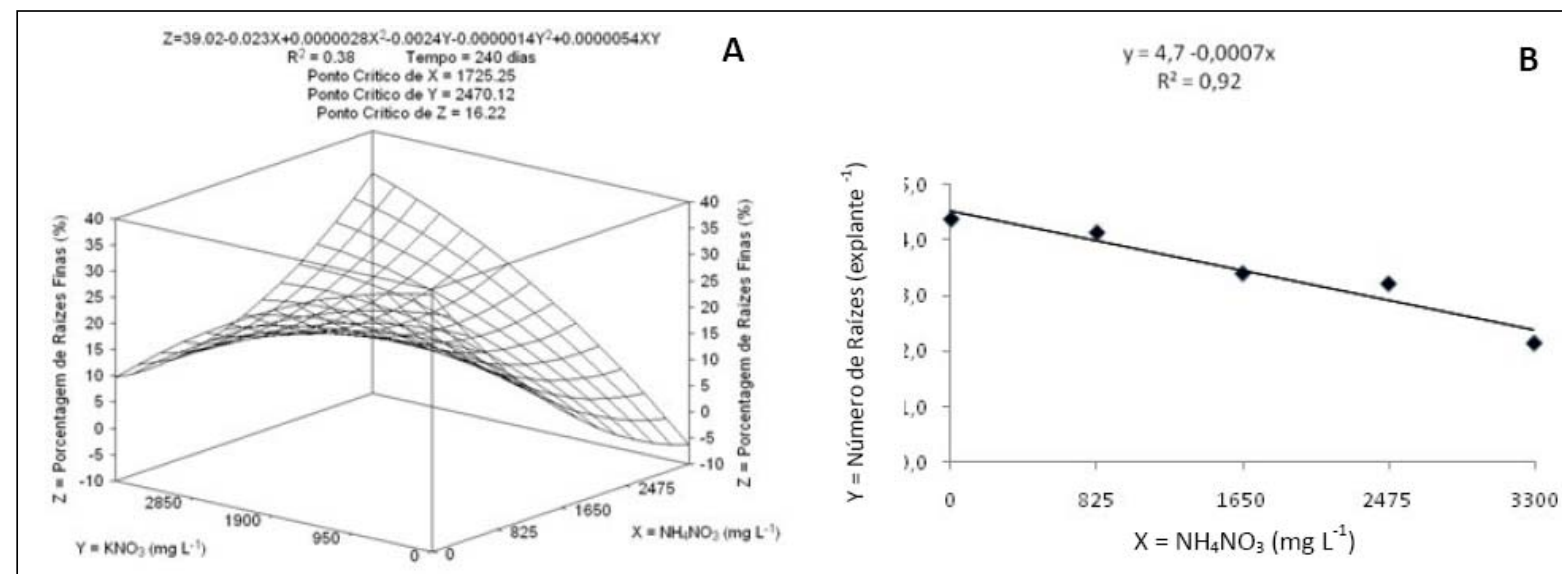

C
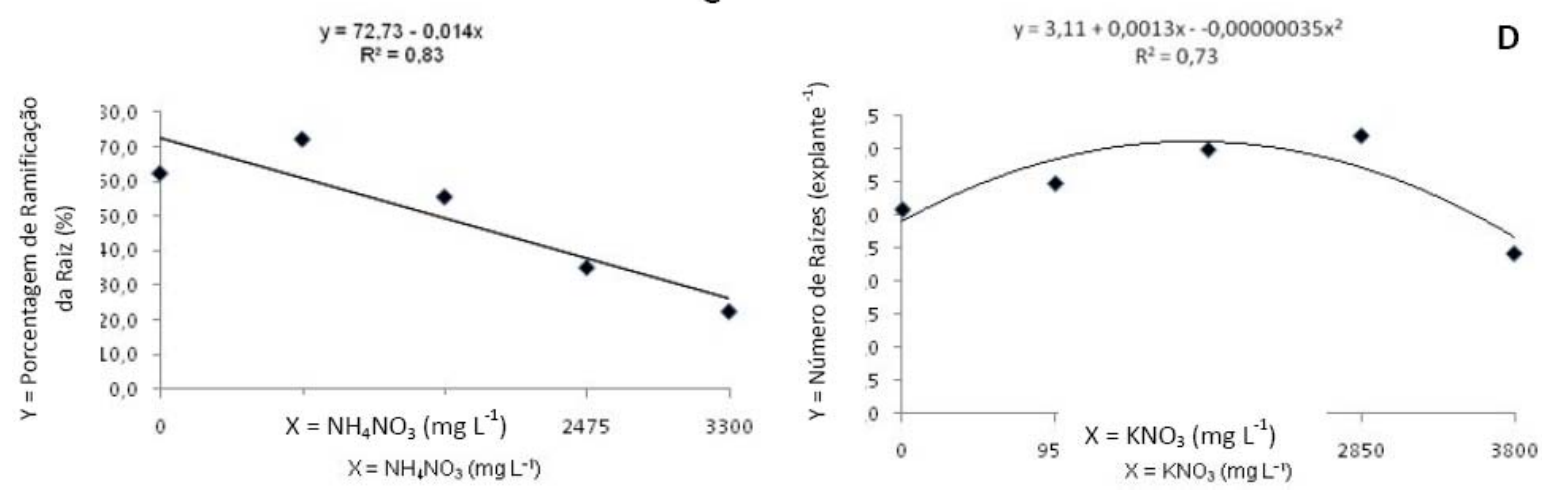

Figura 2 - Porcentagem de raízes finas ( $\mathrm{RF}<1 \mathrm{~mm}$ de diâmetro) (A) de microplantas de $\boldsymbol{B}$. gasipaes desenvolvidas a partir de embriões somáticos em função das concentrações de $\mathrm{NH}_{4} \mathrm{NO}_{3}$ e $\mathrm{KNO}_{3}$, Número de raízes (B), Porcentagem de ramificação da raiz (C) de microplantas de $\boldsymbol{B}$. gasipaes desenvolvidas a partir de embriões somáticos em função das concentrações de $\mathrm{NH}_{4} \mathrm{NO}_{3}$ e Número de raízes (D) de microplantas de B. gasipaes desenvolvidas a partir de embriões somáticos em função das concentrações de $\mathrm{KNO}_{3}$, após 240 dias de cultivo in vitro.

Os resultados obtidos permitem inferir que até 120 dias de cultivo in vitro as microplantas devem ser mantidas em meio de cultura com concentrações menores de $\mathrm{NH}_{4} \mathrm{NO}_{3}$ e maiores de $\mathrm{KNO}_{3}$ que as recomendadas no meio MS, voltando para as doses recomendadas após esse período, facilitando a aclimatização e o desenvolvimento ex vitro.

\section{REFERÊNCIAS}

ALMEIDA, M.; KERBAUY, G.B. Micropropagation of Bactris gasipaes H.B.K. (Palmae) through flower bud culture. Revista Brasileira de Fisiologia Vegetal, v.8, p.215-217, 1996.

ANEFALOS, L.C. et al. Uma visão sobre a pupunheira no contexto do mercado do palmito. Análises e Indicadores do Agronegócio, v.2, n.7, 2007. Disponível em: <http:// www.iea.sp.gov.br/out/verTexto.php?codTexto=9012>. Acesso em: 13 mar. 2009.
BOVI, M.L.A. Expansão do cultivo da pupunheira para palmito no Brasil. Horticultura Brasileira, v.3, n.15, p.183-185, 1997.

GRIME, J.P. et al. Root plasticity, nitrogen capture and competitive ability. In: ATKINSON, D. Plant root growth: an ecological perspective. Oxford: Blackwell Scientific, 1991. p.381-397.

KIRBY, E.G. et al. Nitrogen nutrition. In: BONGA, J.M.; DURZAN, D.J. Cell and tissue culture in forestry. Dordrecht: Martinus Nijhoff, 1987. v.1, p. 237.

MARSCHNER, H. Mineral nutrition of higher plants. London: Academic, 1995. 889p.

MURASHIGE, T.; SKOOG, F. A revised medium for rapid growth and bioassays with tobacco tissue cultures. Physiologia Plantarum, v.15, p. 473-497, 1962.

RIBEIRO, J.M.; TEIXEIRA, S. Substituição de nitrato de potássio (PA) por salitre potássico no preparo de meio de cultura de tecidos vegetais esterilizado com hipoclorito de sódio. Ciência e Agrotecnologia, v.32, n.4, p.1209-1213, 2008. 
SCHEIBLE, W.R. et al. Accumulation of nitrate in the shoot acts as signal to regulate shoot-root allocation in tobacco. Plant Journal, v.11, p.671-691, 1997.

STITT, M. Nitrate regulation of metabolism and growth. Current Opinion in Plant Biology, v.2, n.3, p.178-186, 1999.
TOMBOLATO, A.F.C.; COSTA, A.M.M. (Ed.). Micropropagação de plantas ornamentais. Campinas: Instituto Agronômico, 1998. 72p. (Boletim técnico, 174).

TONET, R.M. et al. A cultura da pupunheira. Campinas: CATI, 1999. 44p. (Boletim Técnico, 237). 